Stéphane Vignot, Jean-Charles Soria, Frédéric Commo, and Fabrice André, Institut National de la Santé et de la Recherche Médicale (INSERM) U981; Vladimir Lazar, Unité de Génomique Fonctionnelle, Institut Gustave Roussy, Villejuif; Christian Brambilla, Denis Moro-Sibilot, and Elisabeth Brambilla, Centre Hospitalier Universitaire Albert Michallon, INSERM U823, Grenoble, France; Garrett M. Frampton, Roman Yelensky, Gary Palmer, Jeffrey S. Ross, Maureen T. Cronin, Philip J. Stephens, Vincent A. Miller, Foundation Medicine, Cambridge, MA.

Published online ahead of print at www.jco.org on April 29, 2013.

Supported by Grants No. HEALTH-F22010-258677 from the European

Commission's Seventh Framework Programme CURELUNG and No. 20091-RT-11 from the French National Cancer Institute.

Presented in part at the 48th Annual Meeting of the American Society of Clinical Oncology, Chicago, IL, June $1-5,2012$

Authors' disclosures of potential conflicts of interest and author contributions are found at the end of this article.

Corresponding author: Jean-Charles Soria, MD, PhD, INSERM U981, Institut Gustave Roussy, 39 Rue Camille Desmoulins, 94805 Villejuif, France; e-mail: soria@igr.fr

(C) 2013 by American Society of Clinical Oncology

0732-183X/13/3117w-2167w/\$20.00 DOI: 10.1200/JCO.2012.47.7737

\title{
Next-Generation Sequencing Reveals High Concordance of Recurrent Somatic Alterations Between Primary Tumor and Metastases From Patients With Non-Small-Cell Lung Cancer
}

Stéphane Vignot, Garrett M. Frampton, Jean-Charles Soria, Roman Yelensky, Frédéric Commo, Christian Brambilla, Gary Palmer, Denis Moro-Sibilot, Jeffrey S. Ross, Maureen T. Cronin, Fabrice André, Philip J. Stephens, Vladimir Lazar, Vincent A. Miller, and Elisabeth Brambilla

\section{$\begin{array}{lllllllll}\text { A } & \text { B } & \text { S } & \text { T } & \text { R } & \text { A } & \text { C } & \text { T }\end{array}$}

\section{Purpose}

Characterization of the genomic changes that drive an individual patient's disease is critical in management of many cancers. In patients with non-small-cell lung cancer (NSCLC), obtaining tumor samples of sufficient size for genomic profiling on recurrence is often challenging. We undertook this study to compare genomic alterations identified in archived primary tumors from patients with NSCLC with those identified in metachronous or synchronous metastases.

\section{Patients and Methods}

Primary and matched metastatic tumor pairs from 15 patients were analyzed by using a targeted next-generation sequencing assay in a Clinical Laboratory Improvement Amendments laboratory. Genomic libraries were captured for 3,230 exons in 182 cancer-related genes plus 37 introns from 14 genes often rearranged in cancer and sequenced to high coverage.

\section{Results}

Among 30 tumors, 311 genomic alterations were identified of which 63 were known recurrent (32 in primary tumor, 31 in metastasis) and 248 were nonrecurrent (likely passenger). TP53 mutations were the most frequently observed recurrent alterations (12 patients). Tumors harbored two or more (maximum four) recurrent alterations in 10 patients. Comparative analysis of recurrent alterations between primary tumor and matched metastasis revealed a concordance rate of $94 \%$ compared with $63 \%$ for likely passenger alterations.

\section{Conclusion}

This high concordance suggests that for the purposes of genomic profiling, use of archived primary tumor can identify the key recurrent somatic alterations present in matched NSCLC metastases and may provide much of the relevant genomic information required to guide treatment on recurrence.

\section{J Clin Oncol 31:2167-2172. (C) 2013 by American Society of Clinical Oncology}

\section{INTRODUCTION}

Lung cancer continues to be the leading cancer killer of both men and women, and the vast majority of such patients die from metastatic disease. ${ }^{1,2}$ More than $80 \%$ of these tumors are non-small-cell lung cancers (NSCLCs), the most frequent histologic types being adenocarcinoma, squamous cell carcinoma, and large-cell carcinoma. NSCLC has become a prototype for personalized therapy in oncology because this disease, particularly the adenocarcinoma subtype, has been segmented by multiple oncogenic "driver" events such as EGFRactivating mutations and $A L K$ and ROS fusions, each of which may be treated with unprecedented success by selected small-molecule tyrosine kinase inhibitors. ${ }^{3}$ The large number of somatic mutations commonly reported in NSCLC is generally attributed to the cocktail of carcinogens in tobacco smoke. This presents the significant challenge of distinguishing somatic alterations in key cancer genes from passenger alterations, which can be further complicated by global genomic instability. Reliable detection of and the ability to distinguish biologically relevant genomic alterations represent a critical challenge in oncology in general and in lung cancer more specifically. In this study, we have defined the genomic alterations that occur in $\geq 5 \%$ of NSCLC samples in the Catalogue of Somatic Mutations in Cancer (COSMIC) or are 
amplified or deleted in $\geq 5 \%$ of NSCLC samples in the literature as "recurrent alterations" and all other alterations as "likely passenger alterations."

In advanced NSCLC, core biopsy specimens and fine-needle aspirates tend to be small in size and relatively impure due to high levels of stromal contamination. However, a subset of these patients had previously undergone surgery for NSCLC, and whether these archival specimens could accurately capture the critical genomic alterations present on recurrence has not been well studied. This question has important biologic and practical clinical implications because rebiopsy in lung cancer can pose a significant risk to the patient and may not always be possible, depending on the metastatic site and underlying patient condition, particularly in a disease that is often coexistent with tobacco-related comorbid conditions such as chronic obstructive pulmonary disease and cardiovascular disease. ${ }^{4}$ Discrepancies have previously been reported for biomarker concordance in metastatic NSCLC, but most studies were restricted to a small set of biomarkers. Scant data are available from comprehensive genome profiling approaches. ${ }^{5}$ In contradistinction, a recent study in renal cell carcinoma suggests that more powerful techniques may more fully inform our understanding of potential discrepancies between a primary tumor and its associated metastasis. ${ }^{6}$ We undertook this study to determine the extent of molecular variability between primary tumors and matched metastasis for NSCLC, with a special focus on known recurrent somatic alterations that had an established role in the pathogenesis of NSCLC. Paired primary-metastatic samples from patients with NSCLC who had experienced disease recurrence were analyzed by next-generation sequencing technology, and global genomic discrepancies were considered as well as discrepancies specific for recurrent somatic alterations (biologically relevant alterations) and other alterations (likely passenger).

\section{PATIENTS AND METHODS}

\section{Inclusion Criteria}

Primary and matched metastatic tumor pairs plus adjacent normal tissue were identified at the Centre of Resources Biologiques of Albert Michallon Hospital, University of Grenoble, France, with International Organization for Standardization 9001 (ISO 9001) certification. Archived surgical samples for both primary tumor and matched metastasis were required to have tumor cellularity above $50 \%$. Complete clinical data have been collected as well as informed consent. Samples were archived from 1988 to 2009 and analyzed concomitantly in 2011.

\section{DNA Extraction}

After the pathologist selected frozen tissue and tumor content was enriched to an estimated $50 \%$ in the selected frozen block, sections of $20 \mu \mathrm{m}$ were cut in a cryostat and were disrupted and homogenized chemically (added in RLT plus buffer (Qiagen, Courtaboeuf, France) with $\beta$-mercaptoethanol (Sigma Aldrich, Saint-Quentin Fallavier, France). The disruption was finallised mechanically, in ice, with a Rotor-stator homogenizer (Kimble Chase Scientific, Vineland, New Jersey). The extraction was performed with the AllPrep DNA/RNA Mini Kit (Qiagen) for simultaneous purification of genomic DNA and total RNA from the same tissue sample. DNA was quantified by spectrophotometry with NanoDrop 1000 (Thermo Scientific, Waltham, MA). DNA is qualified by agarose gel electrophoresis bioanalyzer (Agilent, Santa Clara, CA). Hybridizations were controlled for quality by using the quality control reports generated by Feature Extraction software (Agilent), manual inspection of scans, and in-house scripts for spatial bias identification and distribution of signals verification. The quality of hybridization was excellent for all arrays performed.

\section{DNA Library Construction and Hybrid Capture}

Molecular barcode-indexed, ligation-based sequencing libraries were constructed by using $200 \mathrm{ng}$ of sheared DNA or total DNA recovered from the sample (if $\geq 50 \mathrm{ng}$ ) when $200 \mathrm{ng}$ was not available. Libraries were hybridization captured with custom biotinylated RNA oligo pools (custom SureSelect kit, Agilent) representing 3,230 exons in 182 cancer-related genes plus 37 introns from 14 genes often rearranged in cancer (189 genes total because seven genes were screened across both exons and introns).

\section{Sequencing and Analysis}

Paired-end sequencing $(49 \times 49$ cycles) was performed by using the HiSeq2000 (Illumina, San Diego, CA) in a Clinical Laboratory Improvement Amendments (CLIA) laboratory (Foundation Medicine). Sequence data from genomic DNA was mapped to the reference human genome (hg19) by using the Burrows-Wheeler Aligner (BWA) ${ }^{7}$ and was processed by using publicly available SAMtools, ${ }^{8}$ Picard (http://picard.sourceforge.net) and the Genome Analysis Toolkit. ${ }^{9}$ Genomic base substitutions and indels were detected by using custom tools optimized for mutation calling in heterogeneous tumor samples on the basis of statistical modeling of sequence quality scores and local sequence assembly. Variations were filtered by using dbSNP_135 (http:// www.ncbi.nlm.nih.gov/projects/SNP/) and a custom artifact database and were then annotated for known and likely somatic mutations by using COSMIC. ${ }^{10}$ Copy number alterations were detected by comparing targeted genomic DNA sequence coverage with a process-matched normal control sample. Genomic rearrangements were detected by clustering chimeric reads mapping to targeted introns. To maximize mutation-detection sensitivity, we validated the test to detect base substitutions at a $\geq 10 \%$ mutant allele frequency with $\geq 99 \%$ sensitivity and to detect indels at a $\geq 20 \%$ mutant allele frequency with $\geq 95 \%$ sensitivity, with a false discovery rate of less than $1 \%$. Recurrent somatic alterations were defined as genomic alterations in genes that are mutated $\geq 5 \%$ in COSMIC, or amplified or deleted at $\geq 5 \%$ in the literature. ${ }^{11-16}$ All alterations that were not classified as recurrent were classified as passenger somatic alterations.

\section{Statistical Analysis}

Linear regression analysis was used to study the correlation between mutation frequencies in matched primary and metastatic tumors, considering only mutations found in at least one of the two paired tumor samples. Fisher's exact test was used to compare the proportion of shared alterations in recurrent versus passenger mutations in the matched tumor samples.

\section{RESULTS}

\section{Population}

Fifteen patients with NSCLC met the inclusion criteria (surgical samples available from both primary and metastasis, tumoral cellularity above $50 \%$, informed consent). Histology was adenocarcinoma $(\mathrm{n}=8)$, squamous cell carcinoma $(\mathrm{n}=3)$, large-cell carcinoma $(\mathrm{n}=2)$, and basaloid carcinoma $(\mathrm{n}=2)$. Patient characteristics are summarized in Table 1 . No patient received molecularly targeted therapy before biopsy of metastatic lesions. Estimated median tumoral cellularity of the selected samples was 70\% (range, 50\% to 90\%) and was similar for primary tumors and metastasis.

\section{Somatic Alterations: Global Analysis}

From the 30 tumors, 311 somatic alterations were identified among the 189 evaluated genes: 161 in primary tumors and 150 in the metastases. Description of alterations in primary tumor and metastasis is provided in Table 2. Details on alterations for each sample are available in the Data Supplement. The tumors of patient 9 did not harbor any genomic alteration in this targeted assay (large-cell carcinoma, smoking history estimated to be 30 pack-years, neoadjuvant chemotherapy). The comparative analysis between primary tumor 


\begin{tabular}{|c|c|c|c|c|c|c|c|c|c|c|c|}
\hline Patient & Sex & $\begin{array}{c}\text { Age } \\
\text { (years) }\end{array}$ & $\begin{array}{l}\text { Smoking } \\
\text { Status }\end{array}$ & $\begin{array}{l}\text { Primary Tumor } \\
\text { Surgery Type }\end{array}$ & $\begin{array}{l}\text { Primary Tumor } \\
\text { Histologic Type }\end{array}$ & $\begin{array}{c}\text { Tumor } \\
\text { Cellularity in } \\
\text { Primary } \\
\text { Tumor }(\%)\end{array}$ & $\begin{array}{l}\text { Chemotherapy for } \\
\text { Early-Stage Disease }\end{array}$ & $\begin{array}{l}\text { Time to } \\
\text { Relapse } \\
\text { (months) }\end{array}$ & $\begin{array}{c}\text { Synchronous } \\
\text { Metastasis }\end{array}$ & Metastatic Site & $\begin{array}{c}\text { Tumor } \\
\text { Cellularity } \\
\text { in } \\
\text { Metastasis } \\
(\%)\end{array}$ \\
\hline 1 & M & 60 & Yes & Lobectomy RLL & Adenocarcinoma & 80 & No & 3 & No & Cutaneous & 70 \\
\hline 2 & $\mathrm{~F}$ & 51 & Yes & Lobectomy LUL & Adenocarcinoma & 70 & $\begin{array}{l}\text { Adjuvant (cisplatin, } \\
\text { vinorelbine) }\end{array}$ & 20 & No & CNS & 50 \\
\hline 3 & $\mathrm{~F}$ & 52 & Yes & Lobectomy RLL & Adenocarcinoma & 70 & No & 17 & No & CNS & 80 \\
\hline 4 & $\mathrm{M}$ & 48 & Yes & Lobectomy RUL & Adenocarcinoma & 90 & No & 58 & No & Distant adenopathy & 80 \\
\hline 5 & $M$ & 41 & No & Lobectomy RLL & Adenocarcinoma & 90 & No & 38 & No & Locoregional & 90 \\
\hline 6 & $\mathrm{M}$ & 59 & Yes & Lobectomy LUL & Adenocarcinoma & 70 & $\begin{array}{l}\text { Neoadjuvant (cisplatin, } \\
\text { vinorelbine) }\end{array}$ & 0 & Yes & Adrenal & 60 \\
\hline 7 & M & 60 & Yes & Lobectomy RUL & Adenocarcinoma & 70 & No & 57 & No & Locoregional & 70 \\
\hline 8 & $M$ & 68 & Yes & Lobectomy RUL & Adenocarcinoma & 80 & No & 14 & No & Locoregional & 90 \\
\hline 9 & M & 54 & Yes & $\begin{array}{l}\text { Mediastinoscopy } \\
\text { (bulky N2) }\end{array}$ & $\begin{array}{l}\text { Large-cell } \\
\quad \text { carcinoma }\end{array}$ & 70 & $\begin{array}{l}\text { Neoadjuvant (cisplatin, } \\
\text { etoposide) }\end{array}$ & 76 & No & CNS & 70 \\
\hline 10 & M & 75 & Yes & Lobectomy RLL & $\begin{array}{l}\text { Large-cell } \\
\quad \text { carcinoma }\end{array}$ & 90 & No & 6 & No & Distant adenopathy & 90 \\
\hline 11 & M & 82 & Yes & Bilobectomy RUL ML & $\begin{array}{l}\text { Basaloid } \\
\text { carcinoma }\end{array}$ & 80 & No & 22 & No & Locoregional & 70 \\
\hline 12 & M & 46 & Yes & Lobectomy RUL & $\begin{array}{l}\text { Basaloid } \\
\text { carcinoma }\end{array}$ & 60 & No & 9 & No & Locoregional & 70 \\
\hline 13 & M & 46 & Yes & Lobectomy ML & $\begin{array}{l}\text { Squamous cell } \\
\text { carcinoma }\end{array}$ & 60 & $\begin{array}{l}\text { Chemotherapy at } \\
\text { relapse* (cisplatin, } \\
\text { vinorelbine) }\end{array}$ & 12 & No & Locoregional & 70 \\
\hline 14 & $M$ & 48 & Yes & Lobectomy LLL & $\begin{array}{l}\text { Squamous cell } \\
\text { carcinoma }\end{array}$ & 80 & No & 0 & Yes & Locoregional & 80 \\
\hline 15 & M & 57 & Yes & Left pneumonectomy & $\begin{array}{l}\text { Squamous cell } \\
\text { carcinoma }\end{array}$ & 50 & $\begin{array}{l}\text { Adjuvant (cisplatin, } \\
\text { vinorelbine) }\end{array}$ & 19 & No & Parietal & 60 \\
\hline
\end{tabular}

and matched metastasis includes 170 unique mutations and 21 large structural changes. No gene fusions were identified in this study. The global rate of concordance was 63.9\% (64.5\% for mutations, 59.0\% for large structural changes). Hierarchical clustering aggregated primary tumor and matched metastasis but did not reveal any clustering according to pathologic subtype or chemotherapy as expected because of the number of driver mutations potentially affecting specifically any histologic subtype as compared with the number of cases of each histology. However, the recurrent mutations fit with the histologic type (Fig 1). ${ }^{15,17}$

\section{Recurrent Somatic Alterations Versus Likely Passenger Alterations}

Sixty-three (20\%) among the 311 alterations have previously been reported as recurrent in NSCLC ${ }^{11-16}: 32$ in primary tumor and 31 in metastasis. A description of the recurrent somatic alterations is provided in Table 3 and distribution by patient is illustrated in Appendix Figure A1 (online only). There were 26 different short alteration events (substitutions and indels) in nine genes and five large structural alterations (amplifications and deletions) in four genes.

TP53 mutations were the most frequently observed recurrent alteration (12 patients). Tumors harbored two or more (maximum four) recurrent alterations in 10 patients. An EGFR mutation (L861R) was identified in one patient in both the primary and metastasis (patient 7, adenocarcinoma) in association with a TP53 mutation. No tumor with an ALK rearrangement was identified in this study. No recurrent alteration was identified for two patients.

The comparative analysis between primary tumor and matched metastasis for 33 recurrent alterations compared with 159 likely passenger alterations is summarized in Table 4 and illustrated in Appendix Figure A1 (online only). This analysis reveals a concordance of 94\% for all recurrent alterations compared with 63\% for likely passenger alterations. No discrepancy was observed for the five large structural recurrent alterations, and concordance was 93\% for recurrent mutations versus $61 \%$ for likely passenger mutations (Fisher's exact test $P<.001)$.

\begin{tabular}{|c|c|c|c|c|c|c|c|}
\hline Tumor Status & $\begin{array}{c}\text { Nonsynonymous } \\
\text { Mutations }\end{array}$ & $\begin{array}{l}\text { Synonymous } \\
\text { Mutations }\end{array}$ & $\begin{array}{l}\text { Insertion } \\
\text { Deletion }\end{array}$ & $\begin{array}{l}\text { Homozygous } \\
\text { Deletion }\end{array}$ & Amplification & $\begin{array}{l}\text { Large Structural } \\
\text { Alterations }\end{array}$ & Total \\
\hline Primary & 95 & 27 & 6 & 4 & 12 & 17 & 161 \\
\hline Metastasis & 85 & 25 & 8 & 5 & 10 & 17 & 150 \\
\hline Total & 180 & 52 & 14 & 9 & 22 & 34 & 311 \\
\hline
\end{tabular}




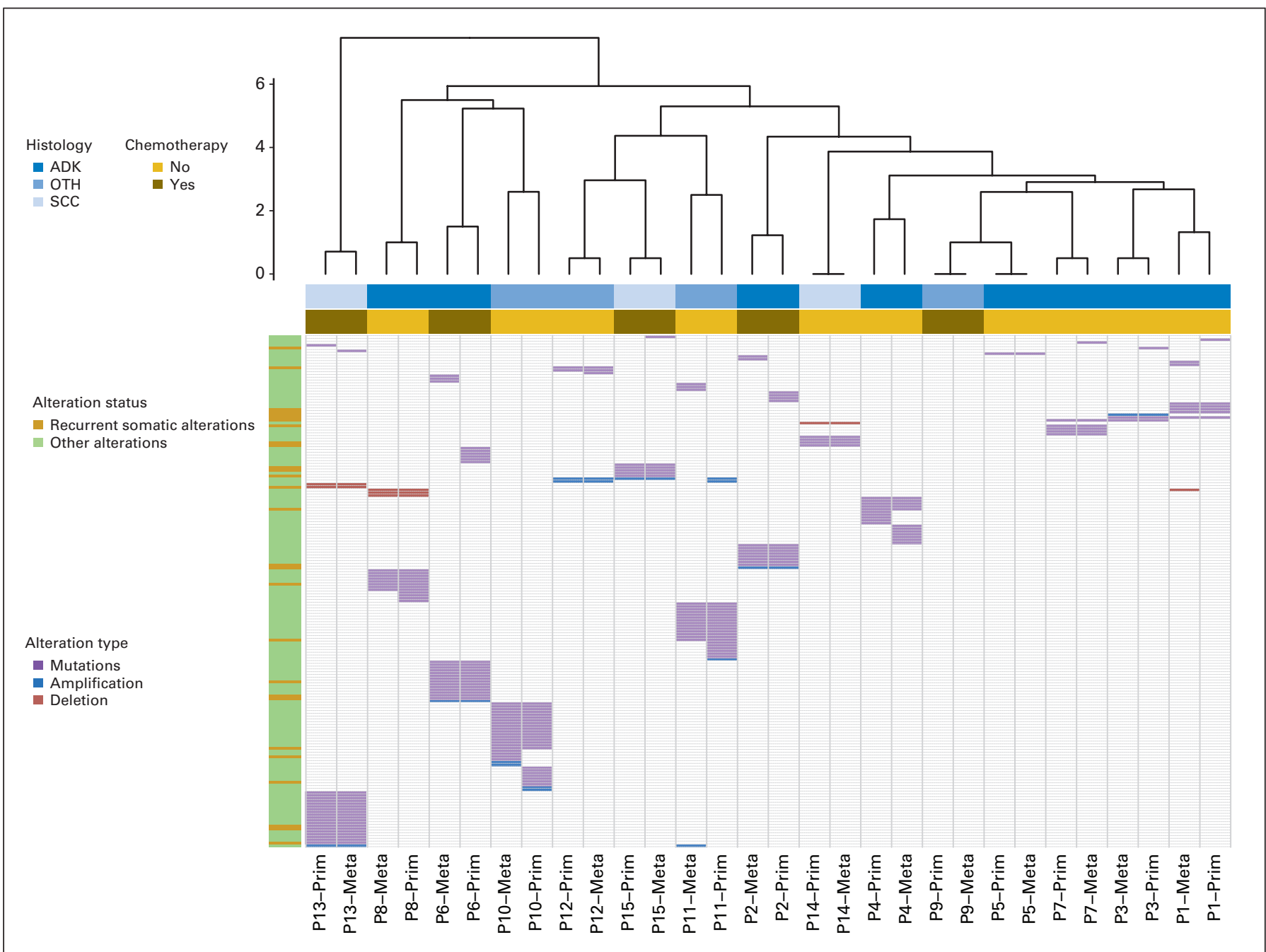

Fig 1. Dual hierarchical clustering of genomic alterations in primary tumor and matched metastasis. The dual hierarchical clustering (Ward distance) on samples and genomic alterations (dendrogram masked) shows a strong association between primary tumors and their corresponding metastasis-each primary tumor is first associated with its matched metastasis. This clustering does not reveal any association of samples regarding histology (light/dark blue), treatment (gold), or alteration status (left clustering). ADK, adenocarcinoma; Meta, metastasis; OTH, other; Prim, primary; SCC, squamous cell carcinoma.

\section{DISCUSSION}

The metastatic process is widely viewed as a multistep event involving a succession of acquired genetic and epigenetic events in tumor cells. A succession of modifications and acquisition of new function by metastatic tumor cells is deemed necessary for invasion and dissemination. Thus, high concordance of genomic alterations between a primary tumor and metastatic lesion would, in theory, be unlikely. ${ }^{5} \mathrm{~A}$ recent study highlighted the intratumoral heterogeneity that may occur in primary renal carcinomas and associated metastatic sites, including discrepancies between different metastatic sites and even different regions of the same metastatic lesion. ${ }^{6}$ Nonetheless, despite this seeming diversity, this study showed a high degree of pathway convergence and concordance among known recurrent somatic alterations. As personalized oncology based on genomic alterations present in a given tumor becomes more widely used, a high number of discrepancies between primary tumor and metastasis would support the routine performance of biopsy on recurrence. Thus, we undertook this study to improve our understanding of a critical question in lung cancer biology but also to provide important information to guide clinical practice.

This study in a cohort of patients with resected NSCLC who subsequently developed metastatic disease reveals a high level of concordance for recurrent alterations at first relapse, whereas the global level of discrepancies is higher when considering all detected genomic alterations. Thus, in our series, the status of major alterations in NSCLC oncogenesis in the primary tumor is a robust surrogate for status at first recurrence when no molecular targeted therapy has been received.

These results provide additional, albeit preliminary, support for the concept of branched evolution during oncogenesis. Recurrent alterations may reflect the key driver oncogenic events that could be constant during metastatic progression, although passenger alterations may be linked to genomic instability. Few of the alterations are likely to be infrequently occurring alterations that are important for the cancer process but are not currently known to the scientific community. The vast majority, however, are true passenger alterations. 


\begin{tabular}{|c|c|c|c|c|}
\hline Gene & cDNA Mutation & $\begin{array}{l}\text { Impact on } \\
\text { Protein } \\
\text { Synthesis }\end{array}$ & $\begin{array}{l}\text { No. in } \\
\text { Primary } \\
\text { Tumors }\end{array}$ & $\begin{array}{c}\text { No. in } \\
\text { Metastatic } \\
\text { Tumors }\end{array}$ \\
\hline \multicolumn{5}{|l|}{ Mutations } \\
\hline$E G F R$ & $2582 T>G$ & L861R & 1 & 1 \\
\hline GNAS & $601 C>T$ & R201C & 1 & 1 \\
\hline \multirow[t]{3}{*}{ KRAS } & $34 \mathrm{G}>\mathrm{T}$ & G12C & 1 & 1 \\
\hline & $35 \mathrm{G}>\mathrm{A}$ & G12D & 1 & 1 \\
\hline & $37 \mathrm{G}>\mathrm{T}$ & $\mathrm{G} 13 \mathrm{C}$ & 2 & 2 \\
\hline NOTCH1 & 4140delG & Frameshift & 1 & 1 \\
\hline \multirow[t]{3}{*}{ PIK3CA } & $1357 G>C$ & E4530 & 1 & 1 \\
\hline & $1624 G>A$ & E542K & 1 & 1 \\
\hline & $1633 G>A$ & E545K & 1 & 0 \\
\hline RB1 & $861 \mathrm{G}>\mathrm{T}$ & E287D & 1 & 1 \\
\hline \multirow[t]{2}{*}{ SMARCA4 } & $3169 \mathrm{G}>\mathrm{T}$ & E1057* & 1 & 1 \\
\hline & $2506-2 A>T$ & Splice & 1 & 1 \\
\hline \multirow[t]{3}{*}{ STK11 } & 179_80insA & Frameshift & 0 & 1 \\
\hline & $232 A>G$ & K78E & 1 & 0 \\
\hline & $488 G>A$ & G163D & 1 & 1 \\
\hline \multirow[t]{11}{*}{ TP53 } & 225delT & Frameshift & 1 & 1 \\
\hline & 338_375del & Frameshift & 1 & 1 \\
\hline & $375+1 C>A$ & Splice & 1 & 1 \\
\hline & $406 C>T$ & Q136* & 1 & 1 \\
\hline & $474 \mathrm{CGC}>\mathrm{TTT}$ & $\mathrm{R} 158 \mathrm{~F}$ & 1 & 1 \\
\hline & $511 \mathrm{G}>\mathrm{T}$ & E171* & 1 & 1 \\
\hline & $659 A>G$ & Y220C & 1 & 1 \\
\hline & $743 G>A$ & $\mathrm{R} 2480$ & 1 & 1 \\
\hline & $811 \mathrm{G}>\mathrm{A}$ & E271K & 1 & 1 \\
\hline & $818 \mathrm{G}>\mathrm{T}$ & $\mathrm{R} 273 \mathrm{~L}$ & 2 & 2 \\
\hline & 939_943delAGGAG & Frameshift & 1 & 1 \\
\hline \multicolumn{5}{|c|}{$\begin{array}{c}\text { Large structural } \\
\text { alterations }\end{array}$} \\
\hline CDKN2A & Deletion & & 1 & 1 \\
\hline FGFR1 & Amplification & & 1 & 1 \\
\hline MYC & Amplification & & 1 & 1 \\
\hline SOX2 & Amplification & & 2 & 2 \\
\hline Total & & & 32 & 31 \\
\hline
\end{tabular}

Conservation of mutations has recently been reported in hematology in a study on progression from myelodysplastic syndromes to secondary acute myeloid leukemia. ${ }^{18}$ Interestingly, a high level of concordance in metastatic colon cancer has recently been reported for alterations between primary tumor and matched liver metastasis ( $>90 \%$ concordance for five critical genes: KRAS, NRAS, BRAF, PIK3CA, and TP53). ${ }^{19}$

Our study has several inherent limitations. Our modest sized cohort included a heterogeneous population of various histologic subtypes and metastatic sites. It focused, in general, on patients whose disease recurred after surgery and not on patients who presented with metastatic disease and were biopsied from multiple sites simultaneously or sequentially after targeted therapies. These groups might be inherently different genomically and, in some cases, particularly under the selection pressure of specific targeted therapies such as erlotinib or crizotinib, as has been repeatedly demonstrated. ${ }^{20-22}$ Specifically, resistance to targeted agents is commonly related to the emergence of a resistant clone initially present in a low percentage of cells, emphasizing the role of intratumor heterogeneity in explaining resistance to targeted agents. Despite the low frequency of

\begin{tabular}{|c|c|c|c|c|}
\hline Alterations & $\begin{array}{l}\text { No. of Evaluated } \\
\text { Alterations }\end{array}$ & Shared & Unshared & $\begin{array}{c}\text { Concordance } \\
\text { Rate }(\%)\end{array}$ \\
\hline \multicolumn{5}{|l|}{ Mutations } \\
\hline Recurrent & 28 & 26 & 2 & 93 \\
\hline Passenger & 144 & 88 & 56 & 61 \\
\hline \multicolumn{5}{|c|}{$\begin{array}{c}\text { Large structural } \\
\text { alterations }\end{array}$} \\
\hline Recurrent & 5 & 5 & 0 & 100 \\
\hline Passenger & 15 & 7 & 8 & 40 \\
\hline \multicolumn{5}{|l|}{ Global } \\
\hline Recurrent & 33 & 31 & 2 & 94 \\
\hline Passenger & 159 & 95 & 64 & 63 \\
\hline
\end{tabular}

certain alterations in this latter setting, these can often portend early clinical progression of disease or a shorter duration of benefit. ${ }^{23}$ Our series included only one patient whose tumor harbored an EGFR mutation. However, new targeted therapies are currently under investigation targeting other recurrent alterations detected in our cohort such as PIK3CA, STK11, or FGFR1. The high level of concordance for these alterations is an important observation for future studies that could be designed on the basis of primary tumor analysis, especially in settings in which patient or doctor preference, comorbidity, or cost make procurement of a more contemporary specimen untenable.

In conclusion, our results from a subset of NSCLC tumors reveal a high level of concordance for recurrent somatic alterations, suggesting that genomic profiles of primary tumor reflect the genomic spectrum of the patient's metastatic disease and can identify the key somatic alterations present in matched NSCLC metastases. In these patients, biopsy of metastatic lesion can be hazardous, and samples are often limited in size. Our data indicate that archived primary material could be a suitable specimen for clinical decision on development of metastatic disease. If confirmed in a larger series, such results do not support the routine need for a new biopsy on first recurrence solely for these purposes, since variability in recurrent alterations status is low. However, the need for a new biopsy of a metastatic lesion may be crucial in order to understand acquired resistance, and future studies should focus on the question of putative selection pressure during the disease course of each patient.

\section{AUTHORS' DISCLOSURES OF POTENTIAL CONFLICTS OF INTEREST}

Although all authors completed the disclosure declaration, the following author(s) and/or an author's immediate family member(s) indicated a financial or other interest that is relevant to the subject matter under consideration in this article. Certain relationships marked with a " $U$ " are those for which no compensation was received; those relationships marked with a "C" were compensated. For a detailed description of the disclosure categories, or for more information about ASCO's conflict of interest policy, please refer to the Author Disclosure Declaration and the Disclosures of Potential Conflicts of Interest section in Information for Contributors. Employment or Leadership Position: Garrett M. Frampton, Foundation Medicine (C); Roman Yelensky, Foundation Medicine (C); Gary Palmer, Foundation Medicine (C); Jeffrey S. Ross, Foundation Medicine (C); Philip J. Stephens, Foundation Medicine (C); Vincent A. Miller, Foundation Medicine (C) Consultant or Advisory Role: Maureen T. Cronin, Foundation Medicine (C) Stock Ownership: Garrett M. Frampton, Foundation Medicine; Roman Yelensky, Foundation Medicine; Gary Palmer, Foundation Medicine; Jeffrey S. 
Ross, Foundation Medicine; Maureen T. Cronin, Foundation Medicine; Philip J. Stephens, Foundation Medicine; Vincent A. Miller, Foundation Medicine Honoraria: None Research Funding: Jeffrey S. Ross, Foundation Medicine Expert Testimony: None Other Remuneration: None

\section{AUTHOR CONTRIBUTIONS}

Conception and design: Stéphane Vignot, Garret M. Frampton, Jean-Charles Soria, Roman Yelensky, Gary Palmer, Philip J. Stephens, Vladimir Lazar, Vincent A. Miller, Elisabeth Brambilla
Collection and assembly of data: Stéphane Vignot, Garrett M. Frampton, Jean-Charles Soria, Roman Yelensky, Christian Brambilla, Gary Palmer, Denis Moro-Sibilot, Maureen T. Cronin, Philip J. Stephens, Vladimir Lazar, Vincent A. Miller, Elisabeth Brambilla Data analysis and interpretation: Stéphane Vignot, Garrett M. Frampton, Jean-Charles Soria, Roman Yelensky, Frédéric Commo, Christian Brambilla, Gary Palmer, Jeffrey S. Ross, Maureen T. Cronin, Fabrice André, Philip J. Stephens, Vincent A. Miller, Elisabeth Brambilla

Manuscript writing: All authors Final approval of manuscript: All authors

\section{REFERENCES}

1. Malvezzi M, Bertuccio $P$, Levi $F$, et al: European cancer mortality predictions for the year 2012. Ann Oncol 23:1044-1052, 2012

2. Siegel R, Naishadham D, Jemal A: Cancer statistics, 2012. CA Cancer J Clin 62:10-29, 2012

3. Pao W, Chmielecki J: Rational, biologically based treatment of EGFR-mutant non-small-cell lung cancer. Nat Rev Cancer 10:760-774, 2010

4. Wu CC, Maher MM, Shepard JA: Complications of CT-guided percutaneous needle biopsy of the chest: Prevention and management. AJR Am J Roentgenol 196:W678-W682, 2011

5. Vignot $S$, Besse B, André F, et al: Discrepancies between primary tumor and metastasis: $A$ literature review on clinically established biomarkers. Crit Rev Oncol Hematol 84:301-313, 2012

6. Gerlinger M, Rowan AJ, Horswell $S$, et al: Intratumor heterogeneity and branched evolution revealed by multiregion sequencing. $\mathrm{N}$ Engl J Med 366:883-892, 2012

7. Li H, Durbin R: Fast and accurate short read alignment with Burrows-Wheeler transform. Bioinformatics 25:1754-1760, 2009

8. Li H, Handsaker B, Wysoker A, et al: The Sequence Alignment/Map format and SAMtools. Bioinformatics 25:2078-2079, 2009
9. McKenna A, Hanna M, Banks E, et al: The Genome Analysis Toolkit: A MapReduce framework for analyzing next-generation DNA sequencing data. Genome Res 20:1297-1303, 2010

10. Forbes SA, Bindal N, Bamford S, et al: COSMIC: Mining complete cancer genomes in the Catalogue of Somatic Mutations in Cancer. Nucleic Acids Res 39:D945-D950, 2011

11. Ding L, Getz G, Wheeler DA, et al: Somatic mutations affect key pathways in lung adenocarcinoma. Nature 455:1069-1075, 2008

12. Pao $W$, Girard N: New driver mutations in non-small-cell lung cancer. Lancet Oncol 12:175180, 2011

13. Pao W, lafrate AJ, Su Z: Genetically informed lung cancer medicine. J Pathol 223:230240, 2011

14. Kohler LH, Mireskandari $M$, Knösel T, et al: FGFR1 expression and gene copy numbers in human lung cancer. Virchows Arch 461:49-57, 2012

15. Cancer Genome Atlas Research Network: Comprehensive genomic characterization of squamous cell lung cancers. Nature 489:519-525, 2012

16. Reungwetwattana T, Weroha SJ, Molina JR: Oncogenic pathways, molecularly targeted therapies, and highlighted clinical trials in non-small-cell lung cancer (NSCLC). Clin Lung Cancer 13:252-266, 2012
17. Perez-Moreno P, Brambilla E, Thomas R, et al: Squamous cell carcinoma of the lung: Molecular subtypes and therapeutic opportunities. Clin Cancer Res 18:2443-2451, 2012

18. Walter MJ, Shen $D$, Ding $L$, et al: Clonal architecture of secondary acute myeloid leukemia. N Engl J Med 366:1090-1098, 2012

19. Vakiani $E_{\text {, Janakiraman } M}$, Shen $R$, et al: Comparative genomic analysis of primary versus metastatic colorectal carcinomas. J Clin Oncol 30: 2956-2962, 2012

20. Sequist LV, Waltman BA, Dias-Santagata $D$, et al: Genotypic and histological evolution of lung cancers acquiring resistance to EGFR inhibitors. Sci Transl Med 3:75ra26, 2011

21. Doebele $R C$, Pilling $A B$, Aisner $D L$, et al: Mechanisms of resistance to crizotinib in patients with ALK gene rearranged non-small cell lung cancer. Clin Cancer Res 18:1472-1482, 2012

22. Suda K, Mizuuchi H, Maehara Y, et al: Acquired resistance mechanisms to tyrosine kinase inhibitors in lung cancer with activating epidermal growth factor receptor mutation: Diversity, ductility, and destiny. Cancer Metastasis Rev 31:807-814, 2012

23. Chmielecki J, Foo J, Oxnard GR, et al: Optimization of dosing for EGFR-mutant non-small cell lung cancer with evolutionary cancer modeling. Sci Transl Med 3:90ra59, 2011 


\section{Appendix}

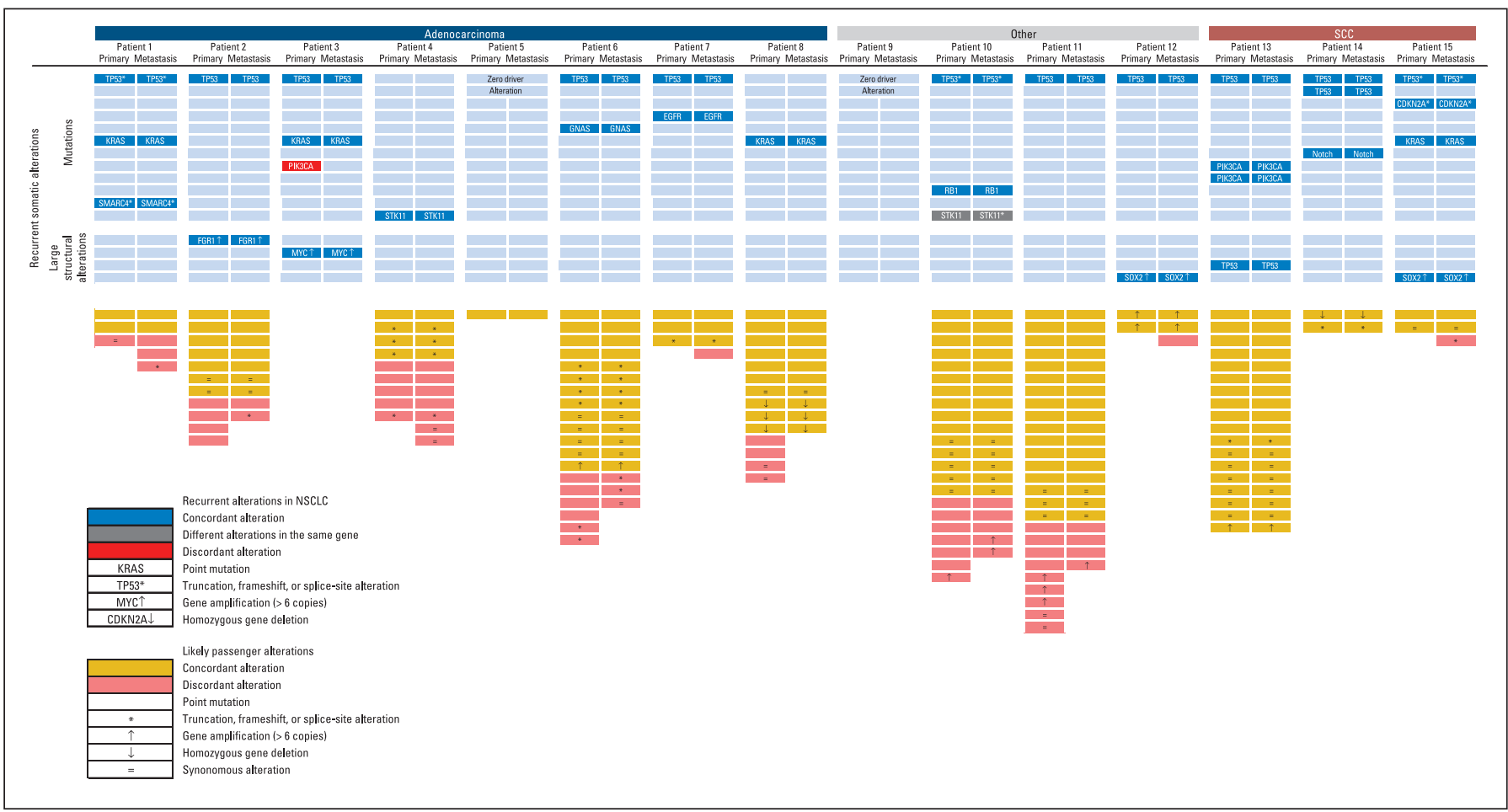

Fig A1. Concordance between primary tumor and matched metastasis for recurrent somatic alterations and likely passenger alterations. NSCLC, non-small-cell lung cancer; SCC, squamous cell carcinoma. 